\title{
Multi-facets of Corticotropin-releasing Factor in Modulating Inflammation and Angiogenesis
}

Eunok Im

College of Pharmacy, Pusan National University, Busan, Korea

The family of corticotropin-releasing factor (CRF) composed of 4 ligands including CRF, urocortin (Ucn) 1, Ucn2, and Ucn3 is expressed both in the central nervous system and the periphery including the gastrointestinal tract. Two different forms of $G$ protein coupled receptors, $\mathrm{CRF}_{1}$ and $\mathrm{CRF}_{2}$, differentially recognize $\mathrm{CRF}$ family members, mediating various biological functions. A large body of evidence suggests that the CRF family plays an important role in regulating inflammation and angiogenesis. Of particular interest is a contrasting role of the CRF family during inflammatory processes. The CRF family can exert both proand anti-inflammatory functions depending on the type of receptors, the tissues, and the disease phases. In addition, there has been a growing interest in a possible role of the CRF family in angiogenesis. Regulation of angiogenesis by the CRF family has been shown to modulate endogenous blood vessel formation, inflammatory neovascularization and cardiovascular function. This review outlines the effect of the CRF family and its receptors on 2 major biological events: inflammation and angiogenesis, and provides a possibility of their application for the treatment of inflammatory vascular diseases.

(J Neurogastroenterol Motil 2015;21:25-32)

Key Words

Angiogenesis effect; Corticotropin-releasing factor; Inflammation; Urocortins

Official abbreviations according to UPHARM guideline were used in this review series.

$\mathrm{CRF}$, corticotrophin-releasing factor

$\mathrm{CRF}_{1}$, corticotrophin-releasing factor receptor 1

$\mathrm{CRF}_{2}$, corticotrophin-releasing factor receptor 2

\section{Introduction}

A family of corticotropin-releasing factor (CRF) is a critical regulator of the hypothalamic-pituitary-adrenal (HPA) axis, leading to subsequent release of adrenocorticotropic factor and corticosteroids. ${ }^{1}$ So far, 4 members of the CRF family are identified: CRF, urocortin (Ucn) 1, and Ucn2 (stresscopin-related peptide), and Ucn3 (stresscopin) (Fig. 1). The CRF family carries out their biological function through their specific receptors, $\mathrm{CRF}_{1}$ and $\mathrm{CRF}_{2}$ which are characterized as G-protein-coupled receptors. ${ }^{2-5} \mathrm{CRF}_{1}$ and $\mathrm{CRF}_{2}$ receptors are diversified into various isoforms such as $\mathrm{CRF}_{1 \alpha}, \mathrm{CRF}_{2 \alpha}, \mathrm{CRF}_{2 \beta}$, and $\mathrm{CRF}_{2 \gamma}$ due to alternate splicing. ${ }^{6}$ Despite the conserved amino acid sequence and the high similarity of their 3 dimensional receptor structure,

Received: July 2, 2014 Revised: October 2, 2014 Accepted: October 4, 2014

(c) This is an Open Access article distributed under the terms of the Creative Commons Attribution Non-Commercial License (http://creativecommons. org/licenses/by-nc/3.0) which permits unrestricted non-commercial use, distribution, and reproduction in any medium, provided the original work is properly cited.

*Correspondence: Eunok Im, PhD

College of Pharmacy, Pusan National University, Busandaehak-ro 63 beon-gil 2, Geumjeong-gu, Busan 609-735, Korea

Tel: +82-51-510-2812, Fax: +82-51-513-6754, E-mail: eoim@pusan.ac.kr

Financial support: This work was supported by National Research Foundation of Korea (NRF) grants from the Korea government (MSIP) (Grant No. 2012R1A1A1042566).

Conflicts of interest: None.

ORCID: http://orcid.org/0000-0002-9949-8819. 


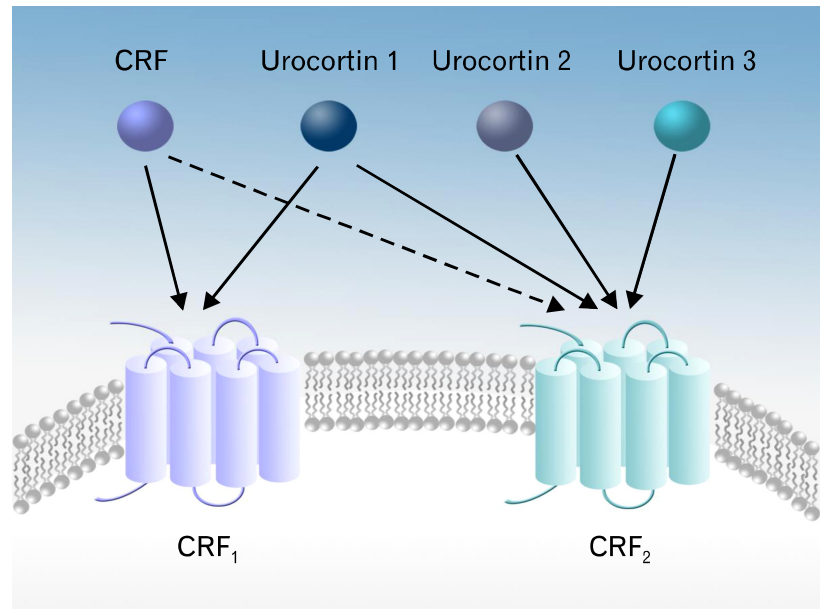

Figure 1. The corticotrophin-releasing factor (CRF) family members and their receptors. The CRF system is composed of natural ligands (CRF and urocortin [Ucn] 1-3) and 2 G-protein-coupled receptors $\left(\mathrm{CRF}_{1}\right.$ and $\left.\mathrm{CRF}_{2}\right) \cdot \mathrm{CRF}_{1}$ and $\mathrm{CRF}_{2}$ receptors exert differential binding affinity to each of the CRF family members. $\mathrm{CRF}_{1}$ receptor binds to $\mathrm{CRF}$ and $\mathrm{Ucn} 1$, while $\mathrm{CRF}_{2}$ receptor binds to $\mathrm{U} c n 1, \mathrm{U} c n 2$, and $\mathrm{U} c \mathrm{c} 3$.
$\mathrm{CRF}_{1}$ and $\mathrm{CRF}_{2}$ receptors have differential binding activities to each of the CRF family members. $\mathrm{CRF}_{1}$ receptor shows high affinity to $\mathrm{CRF}$ and $\mathrm{Ucn} 1$, but no appreciable binding affinity to $\mathrm{Ucn} 2$ and $\mathrm{Ucn} 3 . \mathrm{CRF}_{2}$ receptor primarily binds to $\mathrm{Ucn} 1, \mathrm{Ucn} 2$, and Ucn3 with greater affinity than CRF. Intriguingly, it has been suggested that $\mathrm{CRF}$ and $\mathrm{Ucn} 1$ are able to interact with a secreted glycoprotein, CRF-binding protein, or a soluble splice variant of the $\mathrm{CRF}_{2 \alpha}$ receptor and thereby, provoke an antagonistic effect against the CRF-induced biological activities. ${ }^{7,8}$

Functional diversity of the CRF family and its receptors has been investigated using genetically modified animals (Table). CRF-deficient mice exhibited normal postnatal growth without any apparent abnormalities but the progeny from homozygous CRF-deficient mice all died shortly after their birth due to lung dysplasia suggesting a key role of CRF during embryonic development. ${ }^{9}$ Ucn-deficient mice exhibited increased anxiety-like behaviors through activation of $\mathrm{CRF}_{2}$ receptor, while the HPA axis- mediated stress responses were not different between Ucn-deficient mice and wild-type controls. ${ }^{10} \mathrm{CRF}_{1}$ receptor-deficient mice were characterized with reduced anxiety responses and the progeny born to homozygous $\mathrm{CRF}_{1}$-deficient female mice died within a few days after birth due to lung dysplasia. ${ }^{11} \mathrm{CRF}_{2}$ re-

Table. Phenotypic Characteristics of the Corticotropin-releasing Factor Family or Its Receptor-deficient Mice

\begin{tabular}{|c|c|c|c|}
\hline Genotype & Gross phenotype & Biological characteristics & References \\
\hline CRF-deficient & $\begin{array}{l}\text { Normal postnatal growth, fertility and longevity } \\
\text { Progeny from homozygous died within } 12 \text { hours after } \\
\text { birth due to lung dysplasia } \\
\text { Atrophy of the zona fasciculata of the adrenal gland }\end{array}$ & $\begin{array}{l}\text { Marked glucocorticoid deficiency } \\
\text { Impaired and sexually dimorphic adrenal } \\
\text { stress response }\end{array}$ & Muglia et al, ${ }^{9} 1995$ \\
\hline Ucn-deficient & Normal fertility and no overt phenotype & $\begin{array}{l}\text { Increased anxiety-like behaviors } \\
\text { Normal basal feeding behavior } \\
\text { Normal HPA axis-mediated stress responses } \\
\text { Hearing impairment }\end{array}$ & Vetter et al, ${ }^{10} 2002$ \\
\hline $\mathrm{CRF}_{1}$-deficient & $\begin{array}{l}\text { Normal and fertile when born from heterozygotes } \\
15 \% \text { mortality rate in the male mutant } \\
\text { Progeny from homozygous female died within } 2 \text { days } \\
\text { after birth due to lung dysplasia } \\
\text { Atrophy of the zona fasciculata of the adrenal gland }\end{array}$ & $\begin{array}{l}\text { Low plasma concentration of corticosterone } \\
\text { Impaired stress response } \\
\text { Decreased anxiety response }\end{array}$ & Smith et al, ${ }^{11} 1998$ \\
\hline $\mathrm{CRF}_{2}$-deficient & Normal fertility and no gross abnormality & $\begin{array}{l}\text { Hypersensitive to the HPA axis-mediated } \\
\text { stress response } \\
\text { Increased anxiety-like behavior } \\
\text { Hypertension } \\
\text { Increased blood vessel density }\end{array}$ & Bale et al, ${ }^{12} 2000$ \\
\hline
\end{tabular}

$\mathrm{CRF}$, corticotrophin-releasing factor; $\mathrm{CRF}_{1}, \mathrm{CRF}$ receptor 1; $\mathrm{CRF}_{2}, \mathrm{CRF}$ receptor 2; HPA, hypothalamic-pituitary-adrenal; Ucn, urocortin. 
ceptor-deficient mice were featured with increased anxiety-like behavior and hypersensitive to the HPA axis-mediated stress response. ${ }^{12}$ In addition, $\mathrm{CRF}_{2}$ receptor deficiency exhibited increased vascular density, indicating the postnatal modulation of neovascularization by $\mathrm{CRF}_{2}$ receptor.

Recent evidence suggests that the CRF family is a novel angiogenic regulator in endogenous and inflammatory conditions. ${ }^{13}$ Given that an inflammatory condition is often accompanied with angiogenesis, it has been considered that angiogenesis may aggravate the disease condition. On the other hand, there is a notion that angiogenesis would benefit the recovery process from an inflammatory condition, because angiogenesis can nourish wound healing processes and thereby, improve remission of inflammation. Inflammatory bowel disease (IBD), chronic or acute intestinal inflammatory condition caused by aberrant immune response to gut microflora in genetically susceptible individuals, is the most intensively studied inflammatory conditions, as it is related to the immune modulatory role of the CRF family. ${ }^{13-15}$ Interestingly, the CRF family members can be pro-inflammatory or anti-inflammatory depending on the inflammatory settings and their opposing effect on inflammation appears to result from their implication in angiogenesis. Such dual effects on inflammatory responses can be fulfilled by interleukin (IL)-8 and vascular endothelial growth factor (VEGF) which are potent angiogenic factors. In a way to give an outline of the involvement in human diseases, this review will primarily focus on the impact of the CRF family and receptors in inflammation and angiogenesis.

\section{The Corticotropin-releasing Factor Family and Its Receptors in Intestinal Inflammation}

\section{Pro-inflammatory Effects}

Pro-inflammatory effects of the CRF family have been described in animal studies using various intestinal inflammation models. CRF-deficient mice showed substantially reduced inflammation in trinitrobenzene sulfonic acid (TNBS)-induced experimental colitis with reduced local expression of IL-1 $\beta$ and lowered myeloperoxidase activity which was an indicative of diminished neutrophil infiltration, while colitis-associated systemic changes such as circulating IL-6, anorexia, and weight loss were not altered. ${ }^{16} \mathrm{CRF}$ deficiency was suggested to provide a protective effect against Clostridium difficile toxin A-induced intestinal inflammation (ileitis), characterized with decreased ileal fluid se- cretion, epithelial cell damage, neutrophil transmigration, and mucosal release of substance $\mathrm{P}^{14}$ Moreover, in toxin A-induced ileitis, ileal-specific inhibition of CRF by using a protocol of RNA interference resulted in ameliorated inflammatory responses with reduced mucosal damage and edema, and decreased neutrophil infiltration. In contrast, down-regulation of Ucn2 expression did not alter toxin A-induced acute tissue damage. ${ }^{17}$ In chronic granulomatous enterocolitis induced by intramural injection of peptidoglycan-polysaccharide polymers in the ileocecal region of Lewis rats, CRF $\mathrm{mRNA}$ and protein levels were increased, and thus exogenous CRF treatment in the ileum resulted in enhanced proliferation of laminar propria mononuclear cells, supporting the pro-inflammatory role of $\mathrm{CRF} .{ }^{18}$

In accordance with CRF, CRF receptors receptors were suggested to play a pivotal role during inflammation. Genetic deletion or pharmacological inhibition of $\mathrm{CRF}_{1}$ receptor suppressed the severity of dextran sodium sulfate (DSS)-induced mouse colitis, determined by reduced histological tissue damages and inflammatory cytokine production. ${ }^{13}$ The CRF receptor antagonist, $\alpha$-helical $\mathrm{CRF}_{(9-41)}$ that blocks both $\mathrm{CRF}_{1}$ receptor and $\mathrm{CRF}_{2}$ receptor or the specific $\mathrm{CRF}_{1}$ receptor antagonist antalarmin inhibited toxin A-mediated ileitis along with decreased mucosal content of IL- $1 \beta$ and tumor necrosis factor (TNF)- $\alpha{ }^{19}$ Moreover, enterotoxin-induced ileitis was reduced in $\mathrm{CRF}_{2}$ receptor-deficient mice or the $\mathrm{CRF}_{2}$ receptor specific antagonist astressin 2 -B-treated mice along with decreased mRNA expression levels of keratinocyte chemokine and monocyte chemoattractant protein $1 .{ }^{15}$ Additionally, $\mathrm{CRF}_{2}$ receptor activation by Ucn2 treatment was able to stimulate the expression of IL-8 and monocyte chemoattractant protein 1 in human colonic epithelial HT-29 cells expressing $\mathrm{CRF}_{2 \alpha}$ receptor. ${ }^{15}$ In line with this, RNA interference of $\mathrm{CRF}_{2}$ receptor but not $\mathrm{CRF}_{1}$ receptor dramatically reduced the extent of ulceration during colitis. ${ }^{20}$

It is noteworthy that the expression of the CRF family and its receptor was altered in the inflammatory tissue. The levels of $\mathrm{CRF}, \mathrm{CRF}_{1}$ receptor, and $\mathrm{CRF}_{2}$ receptor expression were increased in the ileum of the mouse treated with intraluminal toxin A. ${ }^{19} \mathrm{Ucn}_{\mathrm{c}}$, but not other Ucns, was significantly up-regulated in the mouse intestine treated with toxin $\mathrm{A}^{15}$ In TNBS-induced rat colitis, the expression of Ucn 1 mRNA fell below basal levels on day 1 and then increased by day 6 along with increased number of inflammatory cells. ${ }^{20}$

In an effort to find an association of CRF with human inflammatory diseases, the CRF family or its receptors were examined in human colonic mucosal tissues obtained from patients 
with ulcerative colitis (UC). Results from immunohistochemical staining showed that laminar propria macrophages had substantially increased CRF expression in the mucosal tissues from UC patients compared to control specimens from normal subjects, suggesting the CRF might be delivered to the inflammatory lesion by mononuclear cells during the pathogenesis of $\mathrm{UC}^{21}$ Moreover, eosinophils were also characterized with increased CRF expression in the colonic mucosa of UC patients, suggesting an involvement of $\mathrm{CRF}$ in colonic mucosal barrier dysfunction and consequently enhanced inflammation. ${ }^{22}$ In the colonic mucosa of UC patients, Ucn1 positive laminar propria cells were correlated with the severity of inflammation suggesting a possible inflammatory role of $\mathrm{Ucn} 1$ and additionally, $\mathrm{CRF}_{1}$ and $\mathrm{CRF}_{2}$ receptor mRNAs were also co-expressed in these cells. ${ }^{23}$ Moreover, in xenografts of human fetal small intestinal and colonic tissues in immune compromised mice after $C$. difficile toxin A challenge, the expression of $U \mathrm{cn} 2$ and $\mathrm{CRF}_{2}$ receptor was increased. ${ }^{24}$ In colonic biopsies from UC patients, total number of $\mathrm{CRF}_{1}$ receptor expressing cells and $\mathrm{CRF}_{1}$ receptor-positive macrophages in the laminar propria were increased by approximately 4-fold compared to the biopsies from healthy subjects and this up-regulation was remained unchanged whether $\mathrm{UC}$ was active or in remission. Therefore, enhanced signaling of $\mathrm{CRF} / \mathrm{Ucns} / \mathrm{CRF}$ receptors receptors might be an important process in the mediation or exacerbation of inflammatory process in $\mathrm{UC}^{25}$

In addition to the intestinal specimens, intriguingly, increased CRF expression was observed in the brain in response to intestinal inflammation. Enhanced $\mathrm{CRF}$ and $\mathrm{CRF}_{1}$ receptor mRNA expression in the paraventricular nucleus of the hypothalamus was observed after TNBS-induced colitis. ${ }^{26}$ Moreover, active colitis led to increased CRF expression in the paraventricular nucleus, and despite resolution of acute colitis, the gene expression persisted. ${ }^{27}$

\section{Anti-inflammatory Effects}

Hypothalamic CRF can exert anti-inflammatory effects. $\mathrm{CRF}$ is known to participate in intestinal inflammatory responses which often occur as a result of stress. Intracerebroventricular injections of CRF inhibited stress-induced aggravation of TNBS-colitis, while central injection of the $\mathrm{CRF}_{1}$ and $\mathrm{CRF}_{2}$ receptor antagonist, astressin worsened colitis. ${ }^{28}$ Putative mechanisms of anti-inflammatory effects of central CRF may include the stimulation of corticosterone secretion. Studies showed that glucocorticoid was able to repress inflammatory responses through inhibition of nuclear factor- $\mathrm{\kappa B}$ and consequently in- hibiting the transcription of pro-inflammatory genes. ${ }^{29,30}$ However, a link between CRF and stress-induced enhancement of colitis still needs to be substantiated. ${ }^{31}$

Peripheral CRF was also suggested to exert the protective effect against intestinal inflammation. CRF-deficient mice were more susceptible to DSS-induced colitis compared to wild-type controls, as represented by increased levels of pro-inflammatory IL-12 and prostaglandin E2 in the colonic tissues. Compared with the wild type mice, CRF-deficient mice were characterized with reduced expression levels of toll-like receptor 4 and MyD88 whose presence could confer protective effects against DSS-induced colitis, suggesting a putative explanation for aggravated intestinal inflammation in CRF-deficient mice. ${ }^{32,33}$

Ucns and their receptors are able to elicit anti-inflammatory responses in the gastrointestinal tract. ${ }^{34} \mathrm{Ucn} 1$ administered intraperitoneally ameliorated the severity of TNBS-induced colitis by not only decreasing inflammatory cytokines including TNF- $\alpha$, IL-6 and regulated on activation, normal $\mathrm{T}$ cell expressed and secreted (RANTES), but also down-regulating T helper 1 driven autoimmune responses together with the involvement of IL-10 and TGF- $\beta$ secreting regulatory cells. ${ }^{35}$ Ucn 3 mRNA expression was diminished by $80 \%$ during TNBS-induced colitis. Besides, colon specific knockdown of $\mathrm{CRF}_{1}$ receptor, but not $\mathrm{CRF}_{2}$ receptor altered Ucn3 expression at baseline and during inflammation in this rat model of colitis, whereas exogenous $\mathrm{Ucn} 3$ treatment did not ameliorate inflammation. ${ }^{36}$

In line with the complicated effect of $U_{c n}$ in the intestinal inflammation, Ucn often shows a biphasic or differential expression level depending on the disease course. In TNBS-induced colitis, Ucn2 mRNA levels markedly increased during the early phase (days 1 and 3), followed by a reduction to the basal levels during the middle phase (days 6 and 9). Then it increased again during the late phase (days 12 and 15 ). In addition, Ucn2 production was increased in a large population of inflammatory cells including lamina propria macrophages. Conversely, Ucn2 specific receptor $\mathrm{CRF}_{2} \mathrm{mRNA}$ expression showed a marked decrease during the early phase of colitis, and then for the remainder of the disease course, the expression was recovered and remained at control levels. Moreover, $\mathrm{CRF}_{2}$ receptor protein was detected only a small fraction of immune cells infiltrated into inflamed lesions. Therefore, increased expression of $U \mathrm{cn} 2$ and its specific receptor $\mathrm{CRF}_{2}$ during the late phase of inflammation suggest that Ucn2 may have a role in resolution of inflammation. In parallel with increased Ucn2 at the early stage of colitis, a decrease of $\mathrm{CRF}_{2}$ receptor at this colitis phase appeared to be a compensatory 
mechanism in order to limit a degree of inflammatory responses in response to the increased ligand. ${ }^{37}$ The contrasting expression pattern between a ligand and a receptor was also observed in another study. The expression of $\mathrm{CRF}_{2}$ receptor was down-regulated in the distal/sigmoid biopsies of UC patients (mild-moderately active $\mathrm{UC}$ and disease in remission: also inflamed) compared to the biopsies from the healthy subjects, suggesting its involvement in the inflammatory process. Receptor expression was prominent in both laminar propria and the epithelial cells in healthy mucosa, but the expression was limited only to laminar propria in inflamed mucosa. In addition, $\mathrm{Ucn} 1$ production was increased in the colonic mucosa of UC patients (moderately active or in remission). ${ }^{38}$ Our group also demonstrated an anti-inflammatory of $\mathrm{CRF}_{2}$ receptor during colitis by showing that $\mathrm{CRF}_{2}$ receptor deficiency exacerbated intestinal inflammation by increasing inflammatory angiogenesis. ${ }^{13}$

\section{The Corticotropin-releasing Factor Family and Its Receptors in Other Inflammation}

Intradermal Ucn 1 treatment induced mast cell degranulation and increased vascular permeability in rat skin, suggesting a pro-inflammatory role of Ucn in dermatitis or psoriasis. ${ }^{34,39}$ In contrast, systemic administration of Ucn inhibited heat-induced paw edema with a greater potency than CRF. ${ }^{40} \mathrm{CRF}, \mathrm{Ucn} 1$, and Ucn2 augmented lipopolysaccharide (LPS)-induced pro-inflammatory cytokine production and increased the expression of toll-like receptor 4 in macrophages through the activation of the transcription factors PU.1 and activator protein-1. ${ }^{41}$ However, in another study, CRF, Ucn1, and Ucn2 transiently suppressed LPS-induced TNF- $\alpha$ production in macrophages during the early phase of inflammation by inducing cyclooxygenase- 2 and prostaglandin E2, whereas longer exposure to CRF and Ucns increased TNF- $\alpha$ production, suggesting an opposing effect. ${ }^{42}$ Ucn inhibited LPS-induced TNF- $\alpha$ production in cultured microglia by inhibiting phosphoinositide 3-kinase/Akt and glycogen synthase kinase- $3 \beta$ pathway, suggesting its anti-inflammatory action. Moreover, in mesencephalic neuron-glia cultures, Ucn inhibited microglial activation and thus protected dopaminergic neurons against LPS-induced neurotoxicity. ${ }^{43}$

Further studies in various inflammatory disease settings also suggested that $U$ cns could have a potential to function as endogenous anti-inflammatory factors. Ucn, a placental peptide, induced secretion of anti-inflammatory cytokines IL-4 and IL-10 from cultured human trophoblast cells isolated from the placentas and reversed LPS-induced TNF- $\alpha$ release through the action of $\mathrm{CRF}_{2}$ receptor. ${ }^{44}$ Moreover, $\mathrm{Ucn}$ exerted a potent therapeutic effect against collagen-induced arthritis by reducing incidence and severity of disease by down-regulating $\mathrm{T}$ helper 1-driven autoimmune response measured by proliferative response and cytokine profile of draining lymph node cells. ${ }^{45}$ In the same study, Ucn also activated IL-10/TGF- $\beta$-producing immune-suppressive regulatory $\mathrm{T}$ cells and thereby suppressing the autoreactive response and restoring immune tolerance. ${ }^{45} \mathrm{Ucn} 1$ treatment was able to prevent lethal septic shock caused by cecal ligation and puncture or injection of bacterial endotoxin by decreasing inflammatory cytokines and chemokines, and the acute phase protein serum amyloid A. ${ }^{46}$ This study suggested an important clinical implication of the CRF family as a therapeutic agent on endotoxemia which is one of the most common causes for death in hospitals. Furthermore, $\mathrm{CRF}_{2}$ receptor and $\mathrm{Ucn} 1$ were suggested as the key mediators of the endoplasmic reticulum stress response in a murine model of acute pancreatic inflammation. Thus, $\mathrm{CRF}_{2}$ receptor -deficient mice showed exacerbated acinar cell inflammation and necrosis accompanied by endoplasmic reticulum damage with increased ubiquitination, peIF2, and mistargeted localization of vimentin. Exogenous Ucn1 rescued histological tissue damages, suggesting its role in resolution of inflammation. ${ }^{47}$

\section{The Corticotropin-releasing Factor Family and Its Receptors in Angiogenesis}

The CRF family and its receptors have been implicated in the regulation of physiological and pathological angiogenesis. An anti-angiogenic activity of $\mathrm{CRF}_{2}$ receptor during vascular development was first identified by Bale et al. ${ }^{48} \mathrm{CRF}_{2}$ receptor-deficient mice showed postnatal hypervascularization of both capillaries and large vessels suggesting an endogenous inhibitory effect of $\mathrm{CRF}_{2}$ receptor. Subsequent in vitro studies showed that Ucn 1 treatment inhibited cell proliferation and VEGF release in rat smooth muscle cells and consequently suppressed angiogenesis of endothelial cells. Moreover, treatment with either CRF or Ucn3 decreased VEGF mRNA expression levels in cultured early placental extravillous trophoblasts and this effect was counteracted by the $\mathrm{CRF}_{2}$ receptor antagonist antisauvagine-30, suggesting the involvement of $\mathrm{CRF}_{2}$ receptor in angiogenesis. ${ }^{49}$ Putative molecular mechanisms for an inhibitory role of $\mathrm{CRF}_{2}$ receptor in angiogenesis involved increased nitric oxide pro- 
duction and down-regulation of hypoxia inducible factor- $1 \alpha$, which in turn decreased VEGF production and thus inhibited angiogenesis. $^{50,51}$

The CRF family and its receptors also regulate pathological angiogenesis. Excessive or abnormal angiogenesis is known to be one of the major characteristics of inflammatory gastrointestinal diseases including IBD and colon cancer. Angiogenesis often facilitates disease progression by promoting the recruitment of immune cells, releasing corresponding cytokines, chemokines and matrix-degrading enzymes, and supplying essential nutrients. ${ }^{52}$ Recent evidence indicates that the CRF family and its receptors can trigger vascular changes during an inflammatory process. Our previous data showed a contrasting effect of $\mathrm{CRF}_{1}$ and $\mathrm{CRF}_{2}$ receptor during endogenous and inflammatory angiogenesis. $\mathrm{CRF} / \mathrm{CRF}_{1}$ receptor promoted endogenous and inflammatory vessel growth, whereas $\mathrm{Ucn} 3 / \mathrm{CRF}_{2}$ inhibited those responses. ${ }^{13}$ Moreover, in human aortic endothelial cells blocking $\mathrm{CRF}_{1}$ receptor increased TNF-induced vascular adhesion molecule-1 and E-selectin expression. ${ }^{53}$

A role of the CRF family and its receptors in tumor angiogenesis has been extensively investigated. For instance, Ucn inhibited angiogenesis through activation of $\mathrm{CRF}_{2}$ receptor and subsequently suppressed the growth of hepatocellular carcinoma as well as small cell lung carcinoma cells. ${ }^{54,55}$ Moreover, almost complete loss of $\mathrm{CRF}_{2}$ expression in hypervascularized renal cell carcinoma supported an idea of $\mathrm{CRF}_{2}$ as an endogenous inhibitor of angiogenesis. ${ }^{56}$ Similarly, loss of $\mathrm{CRF}_{2}$ receptor expression was observed in vascular endothelial cells of prostate cancer tissue not in normal prostate tissue. ${ }^{57}$ Additionally, viral expression of Ucn2 inhibited the growth of Lewis lung carcinoma cell tumors in mice by activating $\mathrm{CRF}_{2}$ receptor and subsequently suppressing tumor angiogenesis. ${ }^{58}$ On the contrary, CRF increased tumor growth and angiogenesis in a mouse xenograft model by stimulating endothelial chemotaxis. ${ }^{59}$

Besides, the CRF family has been implicated in various biological functions pertinent to the cardiovascular system including angiogenesis, vasodilation, alteration of blood pressure, and cardioprotection (Fig. 2). Therefore, the CRF family and its receptors can be a potential therapeutic target to intervene vascular diseases such as cancer and chronic inflammatory diseases.

\section{Conclusion}

This review focused on the functions of the CRF family and its receptors for a potential role in the regulation of inflammation and angiogenesis. Since angiogenesis is an underlying cause of numerous human inflammatory diseases including IBD by aggravating inflammatory processes, dual effects of the CRF family
A

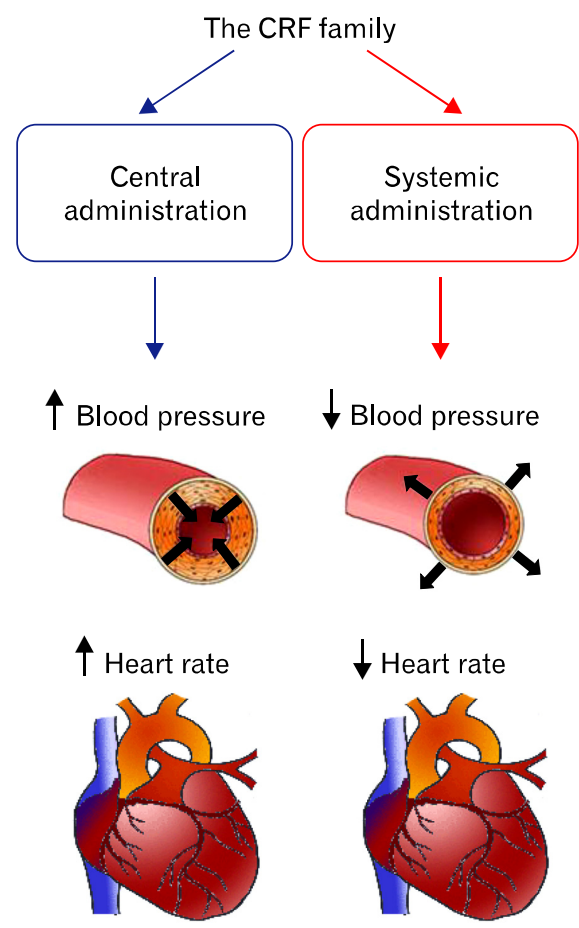

B

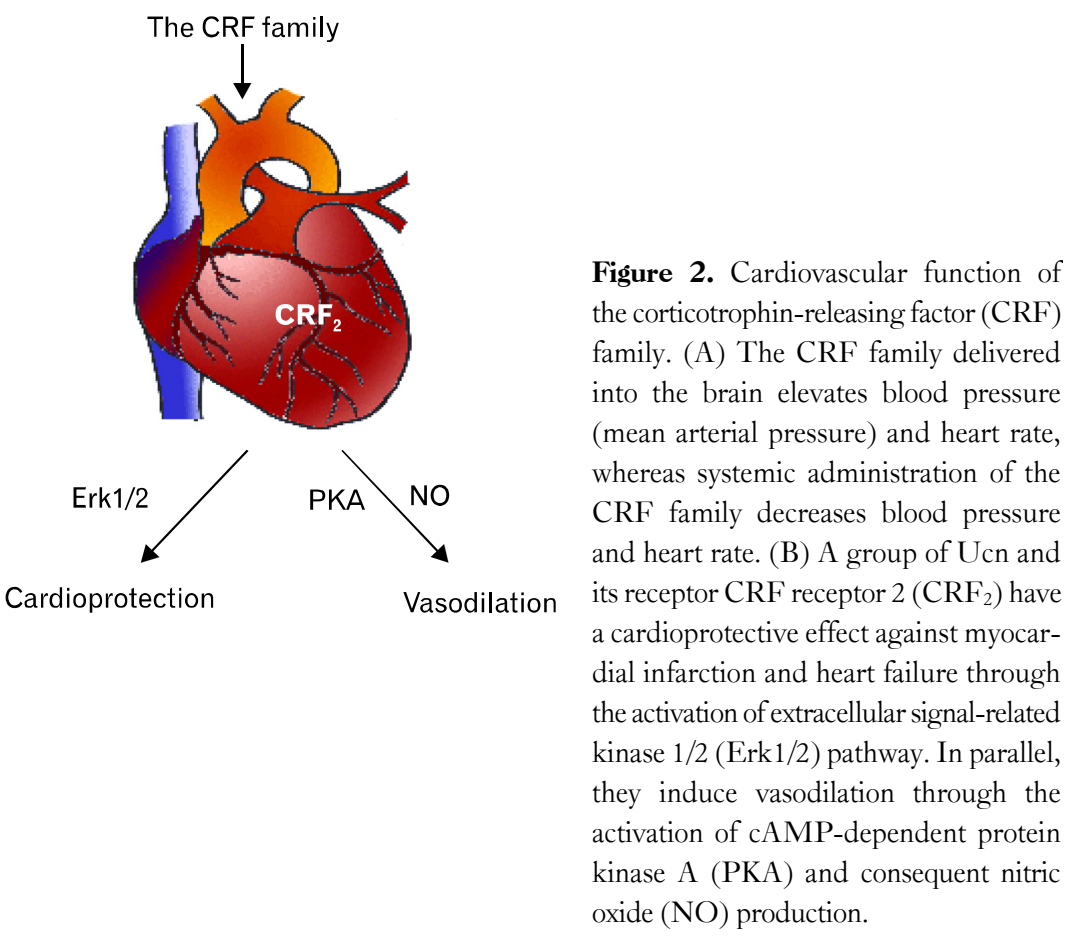


support an idea of its therapeutic application to inflammatory vascular diseases. However, based on the studies mentioned in this review, the CRF family and its receptors exert both pro- and anti-inflammatory as well as pro- and anti-angiogenic responses depending on the experimental settings, which makes matters more complicated and thus limits their applications. Thus, the complexity of the CRF system, the tissue and organ specificity of its function, conflicting experimental results, and contrasting mechanisms of action warrant further investigation. Regardless, the possible implication of agonists or antagonists of the CRF family and its receptors may provide a new pharmacologic platform.

\section{References}

1. Vale W, Spiess J, Rivier C, Rivier J. Characterization of a 41-residue ovine hypothalamic peptide that stimulates secretion of corticotropin and beta-endorphin. Science 1981;213:1394-1397.

2. Vaughan J, Donaldson C, Bittencourt J, et al. Urocortin, a mammalian neuropeptide related to fish urotensin I and to corticotropinreleasing factor. Nature 1995;378:287-292.

3. Lewis $\mathrm{K}, \mathrm{Li} \mathrm{C}$, Perrin $\mathrm{MH}$, et al. Identification of urocortin III, an additional member of the corticotropin-releasing factor (CRF) family with high affinity for the CRF2 receptor. Proc Natl Acad Sci USA 2001;98:7570-7575.

4. Reyes TM, Lewis K, Perrin MH, et al. Urocortin II: a member of the corticotropin-releasing factor (CRF) neuropeptide family that is selectively bound by type 2 CRF receptors. Proc Natl Acad Sci USA 2001;98:2843-2838.

5. Hillhouse EW, Grammatopoulos DK. The molecular mechanisms underlying the regulation of the biological activity of corticotropin-releasing hormone receptors: implications for physiology and pathophysiology. Endocr Rev 2006;27:260-286.

6. Zmijewski MA, Slominski AT. Emerging role of alternative splicing of CRF1 receptor in CRF signaling. Acta Biochim Pol 2010;57: 1-13.

7. Nishimura E, Billestrup N, Perrin M, Vale W. Identification and characterization of a pituitary corticotropin-releasing factor binding protein by chemical cross-linking. J Biol Chem 1987;262:1289312896.

8. Chen AM, Perrin MH, Digruccio MR, et al. A soluble mouse brain splice variant of type 2 alpha corticotropin-releasing factor (CRF) receptor binds ligands and modulates their activity. Proc Natl Acad Sci USA 2005;102:2620-2625.

9. Muglia L, Jacobson L, Dikkes P, Majzoub JA. Corticotropin-releasing hormone deficiency reveals major fetal but not adult glucocorticoid need. Nature 1995;373:427-432.

10. Vetter DE, Li C, Zhao L, et al. Urocortin-deficient mice show hearing impairment and increased anxiety-like behavior. Nat Genet 2002;31:363-369.

11. Smith GW, Aubry JM, Dellu F, et al. Corticotropin releasing factor receptor 1-deficient mice display decreased anxiety, impaired stress response, and aberrant neuroendocrine development. Neuron 1998;
20:1093-1102.

12. Bale TL, Contarino A, Smith GW, et al. Mice deficient for corticotropin-releasing hormone receptor-2 display anxiety-like behaviour and are hypersensitive to stress. Nat Genet 2000;24:410-414.

13. Im E, Rhee SH, Park YS, Fiocchi C, Taché Y, Pothoulakis C. Corticotropin-releasing hormone family of peptides regulates intestinal angiogenesis. Gastroenterology 2010;138:2457-2467, e1-e5.

14. Anton PM, Gay J, Mykoniatis A, et al. Corticotropin-releasing hormone $(\mathrm{CRH})$ requirement in Clostridium difficile toxin A-mediated intestinal inflammation. Proc Natl Acad Sci USA 2004;101:85038508 .

15. Kokkotou E, Torres D, Moss AC, et al. Corticotropin-releasing hormone receptor 2-deficient mice have reduced intestinal inflammatory responses. J Immunol 2006;177:3355-3361.

16. Gay J, Kokkotou E, O'Brien M, Pothoulakis C, Karalis KP. $\mathrm{CRH}$-deficiency is associated with reduced local inflammation in a mouse model of experimental colitis. Endocrinology 2008;149:34033409.

17. la Fleur SE, Wick EC, Idumalla PS, Grady EF, Bhargava A. Role of peripheral corticotropin-releasing factor and urocortin II in intestinal inflammation and motility in terminal ileum. Proc Natl Acad Sci USA 2005;102:7647-7652.

18. van Tol EA, Petrusz P, Lund PK, Yamauchi M, Sartor RB. Local production of corticotropin releasing hormone is increased in experimental intestinal inflammation in rats. Gut 1996;39:385-392.

19. Wlk M, Wang CC, Venihaki M, et al. Corticotropin-releasing hormone antagonists possess anti-inflammatory effects in the mouse ileum. Gastroenterology 2002;123:505-515.

20. Chang J, Adams MR, Clifton MS, et al. Urocortin 1 modulates immunosignaling in a rat model of colitis via corticotropin-releasing factor receptor 2. Am J Physiol Gastrointest Liver Physiol 2011;300: G884-G894.

21. Kawahito Y, Sano H, Mukai S, et al. Corticotropin releasing hormone in colonic mucosa in patients with ulcerative colitis. Gut 1995; 37:544-551.

22. Wallon C, Persborn M, Jönsson M, et al. Eosinophils express muscarinic receptors and corticotropin-releasing factor to disrupt the mucosal barrier in ulcerative colitis. Gastroenterology 2011;140:15971607.

23. Saruta M, Takahashi K, Suzuki T, Torii A, Kawakami M, Sasano H. Urocortin 1 in colonic mucosa in patients with ulcerative colitis. J Clin Endocrinol Metab 2004;89:5352-5361.

24. Moss AC, Anton P, Savidge T, et al. Urocortin II mediates pro-inflammatory effects in human colonocytes via corticotropin-releasing hormone receptor 2alpha. Gut 2007;56:1210-1217.

25. Yuan PQ, Wu SV, Elliott J, et al. Expression of corticotropin releasing factor receptor type 1 (CRF1) in the human gastrointestinal tract and upregulation in the colonic mucosa in patients with ulcerative colitis. Peptides 2012;38:62-69.

26. Porcher C, Sinniger V, Juhem A, Mouchet P, Bonaz B. Neuronal activity and CRF receptor gene transcription in the brains of rats with colitis. Am J Physiol Gastrointest Liver Physiol 2004;287: G803-G814.

27. Greenwood-Van Meerveld B, Johnson AC, Schulkin J, Myers DA. Long-term expression of corticotropin-releasing factor (CRF) in the paraventricular nucleus of the hypothalamus in response to an acute 
colonic inflammation. Brain Res 2006;1071:91-96.

28. Million M, Taché Y, Anton P. Susceptibility of Lewis and Fischer rats to stress-induced worsening of TNB-colitis: protective role of brain CRF. Am J Physiol 1999;276(4 Pt 1):G1027-G1036.

29. Clark AR. Anti-inflammatory functions of glucocorticoid-induced genes. Mol Cell Endocrinol 2007;275:79-97.

30. Bellavance MA, Rivest S. The HPA - immune axis and the immunomodulatory actions of glucocorticoids in the brain. Front Immunol 2014;5:136.

31. Gué M, Bonbonne C, Fioramonti J, et al. Stress-induced enhancement of colitis in rats: $\mathrm{CRF}$ and arginine vasopressin are not involved. Am J Physiol 1997;272(1 Pt 1):G84-G91.

32. Chaniotou Z, Giannogonas P, Theoharis S, et al. Corticotropin-releasing factor regulates TLR4 expression in the colon and protects mice from colitis. Gastroenterology 2010;139:2083-2092.

33. Rakoff-Nahoum S, Paglino J, Eslami-Varzaneh F, Edberg S, Medzhitov R. Recognition of commensal microflora by toll-like receptors is required for intestinal homeostasis. Cell 2004;118:229241.

34. Singh LK, Boucher W, Pang X, et al. Potent mast cell degranulation and vascular permeability triggered by urocortin through activation of corticotropin-releasing hormone receptors. J Pharmacol Exp Ther 1999;288:1349-1356.

35. Gonzalez-Rey E, Fernandez-Martin A, Chorny A, Delgado M. Therapeutic effect of urocortin and adrenomedullin in a murine model of Crohn's disease. Gut 2006;5 5:824-832.

36. Mahajan S, Liao M, Barkan P, Takahashi K, Bhargava A. Urocortin 3 expression at baseline and during inflammation in the colon: corticotropin releasing factor receptors cross-talk. Peptides 2014;54:58-66.

37. Chang J, Hoy JJ, Idumalla PS, Clifton MS, Pecoraro NC, Bhargava A. Urocortin 2 expression in the rat gastrointestinal tract under basal conditions and in chemical colitis. Peptides 2007;28:1453-1460.

38. Chatzaki E, Anton PA, Million M, et al. Corticotropin-releasing factor receptor subtype 2 in human colonic mucosa: down-regulation in ulcerative colitis. World J Gastroenterol 2013;19:1416-1423.

39. Theoharides TC, Singh LK, Boucher W, et al. Corticotropin-releasing hormone induces skin mast cell degranulation and increased vascular permeability, a possible explanation for its proinflammatory effects. Endocrinology 1998;139:403-413.

40. Turnbull AV, Vale W, Rivier C. Urocortin, a corticotropin-releasing factor-related mammalian peptide, inhibits edema due to thermal injury in rats. Eur J Pharmacol 1996;303:213-216.

41. Tsatsanis C, Androulidaki A, Alissafi T, et al. Corticotropin-releasing factor and the urocortins induce the expression of TLR4 in macrophages via activation of the transcription factors PU.1 and AP-1. J Immunol 2006;176:1869-1877.

42. Tsatsanis C, Androulidaki A, Dermitzaki E, Gravanis A, Margioris AN. Corticotropin releasing factor receptor 1 (CRF1) and CRF2 agonists exert an anti-inflammatory effect during the early phase of inflammation suppressing LPS-induced TNF-alpha release from macrophages via induction of COX-2 and PGE2. J Cell Physiol 2007;210:774-783

43. Wang MJ, Lin SZ, Kuo JS, et al. Urocortin modulates inflammatory response and neurotoxicity induced by microglial activation. J Immunol 2007;179:6204-6214.
44. Torricelli M, Voltolini C, Bloise E, et al. Urocortin increases IL-4 and IL-10 secretion and reverses LPS-induced TNF-alpha release from human trophoblast primary cells. Am J Reprod Immunol 2009;62:224-231

45. Gonzalez-Rey E, Chorny A, Varela N, O'Valle F, Delgado M. Therapeutic effect of urocortin on collagen-induced arthritis by down-regulation of inflammatory and Th1 responses and induction of regulatory T cells. Arthritis Rheum 2007;56:531-543.

46. Gonzalez-Rey E, Chorny A, Varela N, Robledo G, Delgado M. Urocortin and adrenomedullin prevent lethal endotoxemia by downregulating the inflammatory response. Am J Pathol 2006;168:19211930.

47. Kubat E, Mahajan S, Liao M, et al. Corticotropin-releasing factor receptor 2 mediates sex-specific cellular stress responses. Mol Med 2013;19:212-222.

48. Bale TL, Giordano FJ, Hickey RP, et al. Corticotropin-releasing factor receptor 2 is a tonic suppressor of vascularization. Proc Natl Acad Sci USA 2002;99:7734-7739.

49. Wakahashi S, Nakabayashi K, Maruo N, Yata A, Ohara N, Maruo T. Effects of corticotropin-releasing hormone and stresscopin on vascular endothelial growth factor mRNA expression in cultured early human extravillous trophoblasts. Endocrine 2008;33:144-151.

50. Bale TL, Giordano FJ, Vale WW. A new role for corticotropinreleasing factor receptor-2: suppression of vascularization. Trends Cardiovasc Med 2003;13:68-71.

51. Tsurumi Y, Murohara T, Krasinski K, et al. Reciprocal relation between VEGF and NO in the regulation of endothelial integrity. Nat Med 1997;3:879-886.

52. Jackson JR, Seed MP, Kircher CH, Willoughby DA, Winkler JD. The codependence of angiogenesis and chronic inflammation. FASEB J 1997;11:457-465.

53. Inada $\mathrm{Y}$, Ikeda K, Tojo K, Sakamoto M, Takada Y, Tajima N. Possible involvement of corticotropin-releasing factor receptor signaling on vascular inflammation. Peptides 2009;30:365-372.

54. Wang J, Xu Y, Xu Y, et al. Urocortin's inhibition of tumor growth and angiogenesis in hepatocellular carcinoma via corticotrophinreleasing factor receptor 2. Cancer Invest 2008;26:359-368.

55. Wang J, Jin L, Chen J, Li S. Activation of corticotropin-releasing factor receptor 2 inhibits the growth of human small cell lung carcinoma cells. Cancer Invest 2010;28:146-155.

56. Tezval H, Jurk S, Atschekzei F, et al. Urocortin and corticotropin-releasing factor receptor 2 in human renal cell carcinoma: disruption of an endogenous inhibitor of angiogenesis and proliferation. World J Urol 2009;27:825-830.

57. Tezval H, Jurk S, Atschekzei F, Serth J, Kuczyk MA, Merseburger AS. The involvement of altered corticotropin releasing factor receptor 2 expression in prostate cancer due to alteration of anti-angiogenic signaling pathways. Prostate 2009;69:443-448.

58. Hao Z, Huang Y, Cleman J, et al. Urocortin2 inhibits tumor growth via effects on vascularization and cell proliferation. Proc Natl Acad Sci USA 2008;105:3939-3944.

59. Arbiser JL, Karalis K, Viswanathan A, et al. Corticotropin-releasing hormone stimulates angiogenesis and epithelial tumor growth in the skin. J Invest Dermatol 1999;113:838-842. 